This is a pre-copyedited, author-produced version of an article accepted for publication in ELT Journal following peer review. The version of record Scheffler, P. 2009. 'Rule difficulty and the usefulness of instruction' ELT Journal 63/1: 5-12 is available online at:

https://academic.oup.com/eltj/article-abstract/63/1/5/362144? redirectedFrom=fulltext

\title{
Rule difficulty and the usefulness of instruction
}

\section{Paweł Scheffler}

It is now generally agreed that some form of focus on the target code is necessary in adult L2 instruction. One question that remains to be answered is whether all aspects of L2 grammar are equally amenable to pedagogic intervention. A number of researchers have examined the effectiveness of instruction with regard to simple vs. difficult grammar rules. To address this question specifically from the learner's perspective, a questionnaire was administered to two groups of Polish adult learners of English. The first group was asked to assess the difficulty of a number of key areas of English grammar. The second was asked to assess the usefulness of instruction in the same areas. The results indicate that there is a considerable overlap between the judgements of both groups: that is, learners feel they benefit the most from instruction in difficult areas.

\section{Problems with purely experiential instruction}

The term 'experiential instruction' can be used to refer to all those kinds of instruction in which L2 learning is supposed to take place as a result of learners experiencing the target language and using it as a tool for communication. Different aspects of communication have been stressed by different proponents of such non-interventionist teaching. For example, in Krashen and Terrell's (1983) Natural Approach, all that is necessary for L2 acquisition to take place is that learners are provided with comprehensible input. In purely experiential task-based instruction, learners simply interact with one another in the target language while performing various cognitive tasks. In content-based instruction, learners are taught non-linguistic subject matter (e.g. geography) through the medium of the target language.

The assumption that underlies all experiential approaches is that a foreign language can be learnt through communication by harnessing essentially the same mechanisms that are responsible for L1 acquisition. This means that L2 learners develop implicit knowledge of the L2 system, and that they do so incidentally.

The non-interventionist position sketched above can be criticized on two main counts. First, assuming that L2 development can proceed largely implicitly and incidentally may not be valid, at least as far as adult learners are concerned. The fundamental difference between adult L2 learners and child L1 acquirers is that the former possess a powerful problem solving mechanism, which they use consciously to deal with complex systems. Bley-Vroman (1989) proposes that it is this domain independent mechanism that adults use in the process of learning a foreign language. This means that adult L2 acquisition is comparable to the acquisition of other cognitive skills like playing chess. According to Anderson (2000), when general cognitive skills are acquired, the process is neither implicit nor incidental: it begins by learners 
developing explicit declarative knowledge which is gradually proceduralized and automatized. Applying this skill-based model to second language learning means that in order to acquire L2 rules learners need to go through an initial stage in which they consciously focus on the formal features of the target code. The most appropriate syllabus to follow at this stage is the structural syllabus. As learners become more advanced, a leading role in the organization of the teaching program can be taken on by communicative tasks (Swan 2005).

The second major problem with experiential instruction has to do with its effectiveness. This issue has been researched thoroughly in the context of French immersion education in Canada. It has been determined that long-term content-based instruction is effective as far as communicative skills are concerned: learners become fluent, they can communicate their ideas easily, and they are very good at comprehending other people's speech and writing. However, despite years of exposure and communicative practice, they fail to produce output that is grammatically accurate. The problems are so significant that, as a way of dealing with them, Harley (1993) proposes that experiential teaching strategies used in contentbased and communicative instruction should be supplemented by analytical procedures which could, for example, include increasing the salience of selected linguistic features, giving learners opportunities for focused production and providing them with negative evidence. These measures are needed because, as Harley (1993: 247) says, 'an experiential teaching strategy may fail to provide optimal conditions for SLA in a classroom context.'

In the view of some prominent SLA specialists, such optimal conditions for classroom SLA can be achieved by retaining the instructional focus on meaning and communication, and supplementing it with 'on-line' form-focused pedagogic interventions or a secondary code-based component. A number of different proposals have been made in this area, by for example Long and Robinson (1998) and Ellis (2003). They will not be reviewed here; suffice it to say that they all treat the task as the central unit of the teaching process.

\section{Selecting rules for explicit grammar instruction}

There are, then, two main approaches to grammar teaching in current SLA thinking: a skill-based approach and a task-based approach. In the former, conscious and systematic study of grammar rules is regarded as the basis for L2 development. In the latter, instruction is to be based on tasks which induce interaction between learners, with code-focused pedagogic interventions or exercises playing a supporting role.

It is not the goal of this article to argue for or against the adoption of either of the approaches outlined above. The general conclusion to be drawn from the foregoing discussion is that whichever approach one adopts, one is justified in applying explicit code-focused instruction. The extent to which it is employed will of course vary, but the case for supplying it, at least as a means of supplementing experiential instruction, is very strong.

There are a number of issues which need to be considered when deciding which L2 grammar rules to target or prioritize in teaching. One of the most controversial is that of rule difficulty, which is often linked to formal and functional complexity. Unfortunately, in many cases it is hard to decide what makes a rule formally and 
functionally complex. A well known example is the third person singular present tense suffix. For Krashen (1982), it is a formally simple feature, as all we are dealing with is the presence or absence of a single morpheme. For Ellis (1990), it is formally complex because it involves a relationship between two non-contiguous items, i.e. a sentential subject and a verbal suffix. As for the functional status of the suffix, both Krashen and Ellis say that it is functionally simple. However, as DeKeyser (1998: 44) points out, given the number of grammatical categories involved in its interpretation (i.e. person, number and tense), 'its form-function relationship is far from transparent.'

To make matters worse, SLA specialists do not agree on whether instruction should deal with rules that they consider linguistically simple and therefore easy to learn, or whether instruction should target features that are complex and consequently difficult. In Krashen's (1982) view, teachers should address simple grammatical phenomena, whereas for Hulstijn and De Graaff (1994), simple rules can be induced by learners on their own, and teachers should focus on those that are difficult. Moreover, empirical studies of the relationship between the effectiveness of explicit instruction and rule difficulty often produce conflicting results: for example, Green and Hecht (1992: 180) state that explicit instruction works best for 'straightforward, mechanically governed categories', whereas Robinson (1996) found that on a simple rule instructed learners in his study were more accurate than implicit ones, and that on a hard rule the two types of learners were equally accurate. Finally, Ellis (2006) has shown that there may be a relationship between the difficulty of grammatical structures and the type of knowledge that is involved, i.e. explicit or implicit.

The discussion above shows that SLA research into linguistic complexity has so far failed to provide teachers with a clear answer as to how this notion and the notion of rule difficulty relate to explicit grammar instruction. Also, the research so far seems to have neglected the fact that rule difficulty is an individual issue. It is an individual issue in two ways: objectively and subjectively. Objectively speaking, rule difficulty is an individual matter because it depends upon learners' language learning aptitude and analytical abilities. As for subjective difficulty, it is related to learners' perceptions of how difficult a given rule is. In deciding which types of rules to give priority to while teaching, it seems important to consider these subjective perceptions of the relationship between rule difficulty and the usefulness of explicit instruction. If it can be shown that in general learners feel they benefit from, say, difficult rules being explained and practised, then teachers should make sure that that this type of instruction is provided. In this way teachers can both help learners to understand how the target system works, and also make them feel secure by meeting their expectations about the teaching / learning process itself.

In order to determine how learners view the relationship between rule difficulty and the usefulness of explicit instruction I have carried out a questionnaire-based study, which I report on in the next section.

\section{Learner perceptions: data collection}

A questionnaire was administered to two groups of Polish adult learners of English (aged 20 or older). Group A was asked to assess on a scale of 1 to 5 the difficulty of a number of key areas of English grammar. Using the same scale, Group B was asked to assess the usefulness of explicit PPP-type of instruction in the same areas of 
English grammar. The reason for having two separate groups, each answering a different question, instead of one group answering both questions, was to avoid any transfer of answers between the questions.

The choice of the 1 to 5 scale was supposed to reflect the levels of rule difficulty proposed by DeKeyser (2003). Drawing on research into the various roles of instruction in SLA, DeKeyser relates different levels of rule difficulty to different degrees of the usefulness of explicit instruction, and hypothesizes that explicit teaching will be useful for easy, moderate and difficult rules, while not useful in the case of very easy and very difficult rules (because it is not necessary in the first case and not effective in the second):

Table 1: Explicit instruction and various levels of rule difficulty

\begin{tabular}{ll}
\hline \multicolumn{1}{c}{ rule difficulty } & \multicolumn{1}{c}{ role of instruction } \\
\hline very easy & not useful (not necessary) \\
easy & speeding up explicit learning process \\
moderate & stretching ultimate attainment \\
difficult & enhancing later implicit acquisition by increasing chances of noticing \\
very difficult & not useful (not effective) \\
\hline
\end{tabular}

(DeKeyser 2003: 332)

As for usefulness of instruction, the levels on the scale were designated as follows:

1 - not useful at all; 2 - of little use; 3 - moderately useful; 4 - useful; 5 - very useful

There were 50 respondents in each group. All of them were advanced second or third year students of English at a college of modern languages. Since practical English grammar courses form part of the school's curriculum, all the respondents in the study were familiar with this type of instruction. The areas of grammar that were included in the questionnaires closely correspond to those that are covered by students during their training. In some cases the areas are referred to in the questionnaire by part-ofspeech labels. This is actually how they are described in the materials that the students use: for example, under the label 'nouns' students discuss in their classes grammatical phenomena like subject-verb agreement or countability. The category 'tenses' (sometimes described in grammar books as 'compound tenses') covers combinations of tense and aspect.

The questionnaires were administered to groups of about 15 students at a time during their regular class meetings. The students had an unlimited time to complete them. The English translations of the original questionnaires can be found in the Appendix. 


\section{Results and discussion}

Table 2: Assessment results in rank order on the basis of the total score

\begin{tabular}{lcclcc}
\hline \multicolumn{1}{c}{$\begin{array}{c}\text { GROUP A } \\
\text { level of difficulty }\end{array}$} & $\begin{array}{c}\text { total } \\
\text { score }\end{array}$ & $\begin{array}{c}\text { average } \\
\text { score }\end{array}$ & \multicolumn{1}{c}{$\begin{array}{c}\text { GROUP B } \\
\text { usefulness of instruction }\end{array}$} & $\begin{array}{c}\text { total } \\
\text { score }\end{array}$ & $\begin{array}{c}\text { average } \\
\text { score }\end{array}$ \\
\hline 1. tenses & 177.5 & 3.5 & 1. tenses & 232.5 & 4.6 \\
2. prepositions & 166 & 3.3 & 2. modal verbs & 215.5 & 4.3 \\
3. -ing forms and infinitives & 164.5 & 3.3 & 3. conditional sentences & 212 & 4.2 \\
4. modal verbs & 154.5 & 3.1 & 4. passive voice & 209.5 & 4.2 \\
5. conditional sentences & 151 & 3 & 5. reported speech & 195.5 & 3.9 \\
6. reported speech & 149.5 & 3 & 6. -ing forms and infinitives & 182 & 3.6 \\
7. passive voice & 147 & 2.9 & 7. prepositions & 180 & 3.6 \\
8. articles & 141.5 & 2.8 & 8. articles & 176 & 3.5 \\
9. nouns & 119.5 & 2.4 & 9. nouns & 171.5 & 3.4 \\
10. pronouns & 111 & 2.2 & 10.adjectives and adverbs & 169.5 & 3.4 \\
11. adjectives and adverbs & 100.5 & 2 & 11.pronouns & 159.5 & 3.2 \\
\hline
\end{tabular}

The results indicate that there is an overlap between the judgements of both groups: in general, if students consider an area of grammar difficult, they also consider instruction in this area useful. Two categories, namely prepositions and -ing forms and infinitives, do not fit this description: respectively, they rank 2 and 3 in level of difficulty and 7 and 6 in usefulness of instruction. That is, the students consider them difficult areas of English grammar, but also areas in which instruction is relatively ineffective. The reason for this is probably the fact that in both cases learning with the help of traditional grammar materials to a great extent involves committing to memory a large number of idiomatic or idiosyncratic combinations, a process in which explicit instruction is of limited value. If we exclude these two categories from the results, the overlap between the assessments of the two groups becomes even more striking:

Table 3: Assessment results with prepositions and -ing forms / infinitives removed

\begin{tabular}{lll}
\hline & \multicolumn{1}{c}{ Group A } & \multicolumn{1}{c}{$\begin{array}{c}\text { Group B } \\
\text { level of difficulty }\end{array}$} \\
\hline 1. tenses & 1. tenses \\
2. modal verbs & 2. modal verbs \\
3. conditional sentences & 3. conditional sentences \\
4. reported speech & 4. passive voice \\
5. passive voice & 5. reported speech \\
6. articles & 6. articles \\
7. nouns & 7. nouns \\
8. pronouns & 8. adjectives and adverbs \\
9. adjectives and adverbs & 9. pronouns \\
\hline
\end{tabular}

Taking a closer look at the scores (from Table 2) for the categories in Table 3, one can identify four general levels of difficulty and usefulness of instruction:

1. Tenses

2. Modal verbs, conditional sentences, reported speech and passive voice

3. Articles, nouns, and pronouns

4. Adjectives and adverbs 
Since the differences between the scores within levels two and three are rather small, it seems that any recommendations to teachers for prioritizing any specific grammatical items in the process of instruction should be restricted to the general levels distinguished above. Also, before making any such recommendations, one needs to bear in mind that the results of the present study may have been influenced by the L1 background of the subjects. The extent to which this was the case is not clear, however. On the one hand, the high scores of verbal grammatical categories might indicate that the L1 of the subjects does play a part: the Polish verb phrase differs from the English VP in a number of key ways, for example by not possessing auxiliary verbs which could be used to form 'compound tenses' or complex constructions involving modal verbs. On the other hand, Polish does not have the article system, but this does not seem to have pushed the score of this category very high. Research involving learners from different L1 backgrounds is clearly needed to settle this issue.

Another interesting finding emerging from Table 2 is that in general the students consider English grammar to be relatively easy: the average scores for the most difficult and the easiest areas are 3.5 and 2.0 respectively. In relation to DeKeyser's descriptive labels in Table 1, this indicates that the hardest rules in the area of tenses fall just above the moderate level. By contrast, the usefulness of instruction is rated on average much higher: it ranges from 3.2 for pronouns to 4.6 for tenses. The difference between the assessment of difficulty and the assessment of the usefulness of instruction is highly significant statistically: the Wilcoxon matched pairs signed ranks test indicates that it has a significance level of $\mathrm{p}<0.001$.

It seems that the reason why the results for usefulness of instruction were consistently higher than those for difficulty lies in the linguistic and academic profile of the subjects. As has been said, the subjects were advanced learners with extensive experience of the target language, and at the same time English students at a college of modern languages. This means that, in general, they were likely to be people with a good knowledge of English grammar, and with an interest in the formal study of language. The former can explain the assessment of the level of difficulty; the latter can account for the evaluation of instruction.

\section{Conclusion}

The present study is rather limited in a number of respects. First, it deals with learners of English from one particular L1 background. Second, it only describes the perceptions of advanced adult learners selected from an academic population. Third, it does not attempt to relate the subjective notion of difficulty, revealed by the subjects' judgements, to objective difficulty, which could be measured by various types of tests. All of these are, of course, areas which deserve further research.

These limitations notwithstanding, some general conclusions and recommendations can be made. The survey reported in the present paper clearly indicates that the respondents consider explicit grammar teaching useful: the lowest ranking area has an average score of 3.2 on a 1 to 5 scale. Moreover, they regard instruction in difficult areas as particularly useful. It seems reasonable to assume that this underlying relationship between difficulty and usefulness of instruction will not be altered by differences stemming from other L1 contexts. This means that once teachers know which areas their students perceive as difficult (and at least for learners from other 
Slavic backgrounds they are likely to be comparable to the ones uncovered by the present study) they can safely assume that instruction targeting those areas will be welcome.

SLA researchers have not so far been able to achieve consensus on how the linguistic complexity of grammatical structures interacts with learning difficulty. Regardless of the conclusions that may finally be reached, it seems that learner perceptions revealed by studies like the one reported in the present paper should be one of the factors in taking decisions concerning the targets for explicit instruction. If foreign language pedagogy ignores learners' feelings and expectations about the teaching process, its chances of success will be very much reduced.

\section{$\underline{\text { References }}$}

Anderson, J. 2000. Learning and Memory: An Integrated Approach (Second Edition). New York: Wiley.

Bley-Vroman, R. 1989. 'What is the logical problem of second language learning' in S. Gass and J. Schachter (eds.). Linguistic Perspectives on Second Language Acquisition. Cambridge: Cambridge University Press.

DeKeyser, R. M. 1998. 'Beyond focus on form: Cognitive perspectives on learning and practising second language grammar' in C. J. Doughty and J. Williams (eds.).

DeKeyser, R. M. 2003. 'Implicit and explicit learning' in C. J. Doughty and M. H. Long (eds.). The Handbook of Second Language Acquisition. Oxford: Blackwell. Doughty C. J. and J. Williams (eds.). 1998. Focus on Form in Classroom Second Language Acquisition. Cambridge: Cambridge University Press.

Ellis, R. 1990. Instructed Second Language Acquisition. Oxford: Blackwell.

Ellis, R. 2003. Task-based Language Learning and Teaching. Oxford: Oxford University Press.

Ellis, R. 2006. 'Modelling learning difficulty and second language proficiency: The differential contributions of implicit and explicit knowledge' Applied Linguistics 27/3: 431-63.

Green, P. and K. Hecht. 1992. 'Implicit and explicit grammar: An empirical study' Applied Linguistics 13/2: 168-84.

Harley, B. 1993. 'Instructional strategies and SLA in early French immersion' Studies in Second Language Acquisition 15/2: 245-59.

Hulstijn, J. and R. de Graaff. 1994. 'Under what conditions does explicit knowledge of a second language facilitate the acquisition of implicit knowledge. A research proposal' in J. Hulstijn, and R. Schmidt (eds.). Consciousness in Second Language Learning. AILA Review 11.

Krashen, S. D. 1982. Principles and Practice in Second Language Acquisition. Oxford: Pergamon.

Krashen, S. D. and T. D. Terrell. 1983. The Natural Approach. Language Acquisition in the Classroom. Oxford: Pergamon.

Long, M. H. and P. Robinson. 1998. 'Focus on form: Theory, research and practice' in C. J. Doughty and J. Williams (eds.).

Robinson, P. 1996. 'Learning simple and complex second language rules under implicit, incidental, rule-search, and instructed conditions' Studies in Second Language Acquisition 18/1: 27-67.

Swan, M. 2005. 'Legislation by hypothesis: The case of task-based instruction' Applied Linguistics 26/3: 376-401. 


\section{$\underline{\text { Appendix }}$}

In both questionnaires the students were asked to provide the following information about themselves:

Age:

I have been learning English for years.

They were asked the following questions:

\section{Group A}

On a scale of 1 to 5 assess the difficulty of the following areas of English grammar.

\section{Group B}

On a scale of 1 to 5 assess the usefulness of grammar instruction in relation to the following areas of English grammar.

The 1 to 5 scale was explained to the students before they completed the questionnaires.

\begin{tabular}{l|l}
\hline \multicolumn{1}{c|}{ area of grammar } & $\begin{array}{c}\text { level of difficulty (Group A) } \\
\text { usefulness of instruction (Group B) }\end{array}$ \\
\hline modal verbs (e.g. may, can) & \\
\hline pronouns (e.g. none, all, someone) & \\
\hline prepositions (e.g. at, into, with) & \\
\hline tenses & \\
\hline passive voice & \\
\hline conditional sentences & \\
\hline nouns (e.g. countable, uncountable) & \\
\hline articles (a, an, the) & \\
\hline reported speech & \\
\hline adjectives and adverbs (e.g. comparison) & \\
\hline constructions with -ing forms and infinitives & \\
\hline
\end{tabular}

